\title{
Discharge-damage curve and EAD estimates in the Pamplona metropolitan area (Spain) by using insurance data
}

\author{
Luis Mediero $^{1 a}$, Luis Garrote ${ }^{1}$, David Santillán ${ }^{1}$, Luis Cueto-Felgueroso ${ }^{1}$ and Enrique Soriano ${ }^{1}$ \\ ${ }^{1}$ Department of Civil Engineering: Hydraulics, Energy and Environmental, Universidad Politécnica de Madrid, Madrid, Spain
}

\begin{abstract}
Flood risk assessment studies require information about direct damages that can be summarised through the expected annual damage (EAD). The discharge-damage curve for a given location is required to estimate EAD. The Pamplona metropolitan area with around 335,000 inhabitants has been selected as a pilot site, as part of the activities of the EIT Climate-KIC Demonstrator project SAFERPLACES. Insurance flood losses in the Pamplona metropolitan area in the period 1996-2018 were supplied by the Spanish 'Consorcio de Compensación de Seguros' (CCS). A set of flood events with both flood hydrographs and insurance flood losses were selected. Flood extensions and water depths in the Pamplona metropolitan area for such selected flood events were estimated by using a two-dimensional hydrodynamic model, calibrated with the known water extension for a given flood event. A damage model has been developed to estimate direct damages by using a set of water depth-relative damage curves in terms of building occupancy, calibrating the results with the insurance flood losses supplied by CCS. With such results, the dischargedamage curve and EAD were estimated in the metropolitan area of Pamplona.
\end{abstract}

\section{Introduction}

Flood risk assessment studies require information about the damages generated by floods. Feasible options to reduce flood risks must be selected in terms of either cost-benefit (Kind, 2014) or cost-effectiveness (Meyer et al. 2012) analyses. For such analyses, flood damage assessment is required. Flood damages can be classified into direct and indirect (Rose, 2004). Direct damages can be assessed easier than indirect damages, as indirect costs show a time scale of months and are not localised where a flood event occurs.

Direct damages can be quantified by using damage functions that relate damages in assets to a set of flood descriptors, such as flow depth, flow velocity, duration of inundation, sediment concentration, water contamination and flood warning measures, among others (Merz et al., 2010). However, most damage functions only consider flow depths, known as depth-damage curves (Huizinga et al., 2017; Scorzini and Frank, 2017; de Moel and Aerts, 2011).

Depth-damage curves can be either empirical or synthetic (Merz et al., 2010). Empirical depth-damage functions are estimated from damage data collected in past real events by either insurance data or citizen surveys (Carisi et al., 2018). Synthetic depth-damage functions estimate asset damages for a given flood event by using either building damage analyses or damage observations in real events (Schinke et al., 2016; Pistrika et al., 2014).
Empirical depth-damage functions are based on real flood damage information, showing a great accuracy in terms of building uses and water depths. However, such information is usually available for a reduced number of events that do not cover the largest flood events that generate the greatest damages (Smith, 1994). Synthetic approaches can be applied to any location and flood magnitude, regardless the availability of flood damage data collected in real events. However, the results show a higher uncertainty.

The expected annual damage (EAD) is the annual average damage expected in a large number of years, obtained from the annual exceedance probability of flood damages (Arnell, 1989). Therefore, first, a flood frequency curve is required in the study location (Stedinger, 1997). Second, damage quantification for a wide set of flood magnitudes is needed. Moreover, EAD can be useful to assess the influence of climate change on flood risks (te Linde et al., 2011; Budiyono et al., 2016).

Two-dimensional overland flow models can supply estimates of flow depths and velocities and flood duration at the building level (ten Veldhuis, 2011). Several flood loss models have been developed to estimate flood damages by using outputs of 2D hydrodynamic models (Gerl et al., 2016). Most of such flood loss models are based on one-variable damage functions for a set of building uses and types, focusing on damages in the residential sector.

2D hydrodynamic model outputs at the building scale can be coupled with synthetic damage functions in 
buildings to obtain relative flood damages at municipality scales. Absolute flood damages can be obtained by using estimates of building and content values (Paprotny et al., 2020a). In addition, openly available datasets can be used to reanalyse past flood losses, as well as to estimate potential flood damages in the future (Paprotny et al., 2020b).

In this study, a discharge-damage function is estimated in the Pamplona metropolitan area, by coupling a damage model to a $2 \mathrm{D}$ hydrodynamic model. A set of seven flood events with data about flood hydrographs and damages is selected. The $2 \mathrm{D}$ hydrodynamic model is calibrated to obtain the spatial distribution of water depths for the seven real flood events. Mean water depths in buildings are transformed into damages by using a damage model, based on given water depth-relative damage curves for a set of building uses. Insurance data on real flood direct damages collected for the seven events were used to calibrate the damage model by postal codes and municipalities. Results are analysed by postal codes and aggregated by municipalities. Finally, the discharge-damage curve in the Pamplona metropolitan area is estimated, and the EAD is calculated.

In Section 2, the case study and the data collected are presented. Section 3 offers the methodology proposed, coupling the two-dimensional hydrodynamic model to the damage model. Section 4 shows the results. First, the areas and sectors that suffer the greatest flood damages are identified by processing the insurance data. Second, the results of the damage model are presented. Third, the discharge-damage function in the Pamplona metropolitan area is obtained. Section 5 includes the discussion about the limitations of the proposed methodology. Section 6 summarises the main conclusions of the study.

\section{Case study and data}

In this section, first, the case study of the metropolitan area of Pamplona is presented. Second, the data used in the study are described.

\subsection{Case study}

The metropolitan area of Pamplona is the selected case study, as it is one of the three pilot sites of the EIT ClimateKIC Demonstrator project SAFERPLACES. It is located in the Navarre Region in the northern part of Spain (Figure 1). The Pamplona metropolitan area has around 335,000 inhabitants. The River Arga crosses Pamplona with a catchment area of around $500 \mathrm{~km}^{2}$. The rivers Arga and Ulzama confluence just upstream of the study area, with catchment areas of $180 \mathrm{~km}^{2}$ and $270 \mathrm{~km}^{2}$, respectively. The metropolitan area of Pamplona suffers frequent floods. At least 38 flood events have been collected in the period 1900-2018. Three flood generation mechanisms have been identified: (i) frontal rainfall events from October to March, (ii) thaw from December to February, and (iii) convective storms in summer.

In this study, the municipalities that are located in the flood prone area of the River Arga are considered (Figure 2): Burlada (18,934 inhab.), Cendea de Olza
(1,842 inhab.), Huarte (7,014 inhab.), Pamplona (199,066 inhab.) and Villava (10,150 inhab.). The population in each municipality has been obtained from the data collected by the Spanish Institute for Statistics (INE) in 2018.

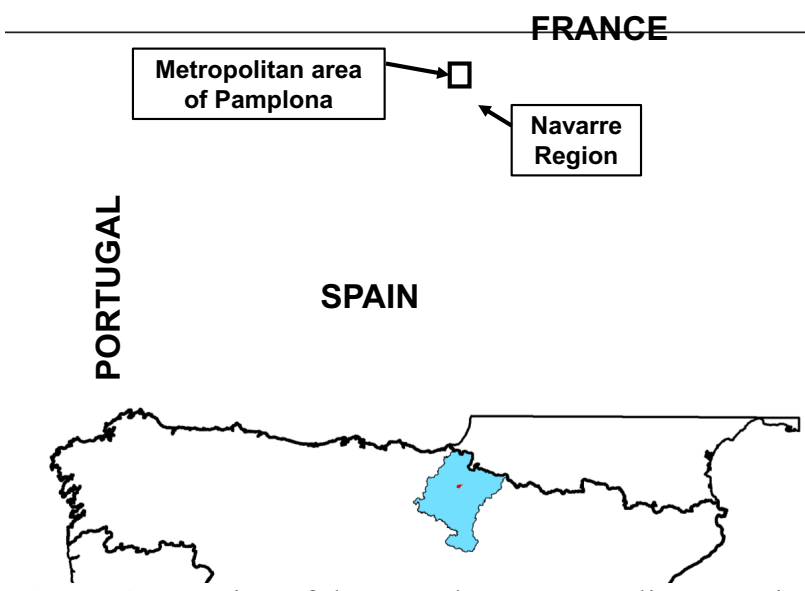

Figure 1. Location of the Pamplona metropolitan area in the Navarre Region in Spain.

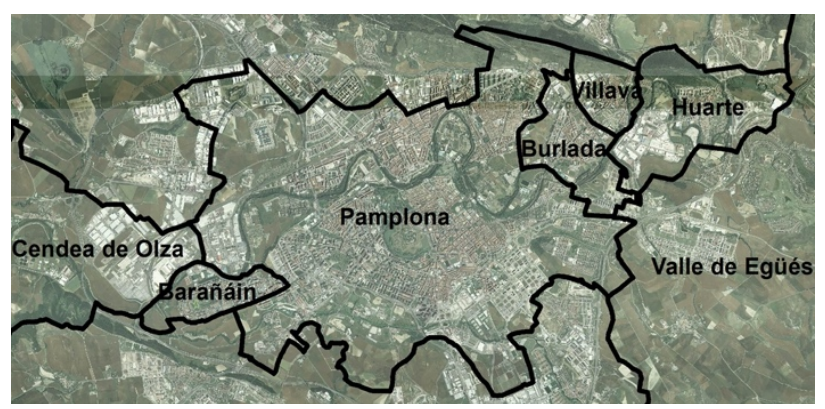

Figure 2. Municipalities in the metropolitan area of Pamplona.

\subsection{Data}

A set of datasets has been collected in the metropolitan area of Pamplona to conduct the study. First, the hydrometeorological data are presented. Second, the damage data are summarised. Third, a set of seven flood events are selected. Fourth, additional data required in the analysis are described.

\subsubsection{Hydrometeorological data}

15-min rainfall and streamflow data in the period 20062019 were supplied by the 'SAIH' real-time system of the Ebro River Basin Authority. Longer daily streamflow time series were supplied by the 'Anuario de Aforos' of the Spanish Ministry of Environment (MITECO). Flood hydrographs with a 15-min time step were extracted from the observations in the gauging stations located in the Rivers Ulzama and Arga upstream their confluence, as well as in the River Arga in Pamplona for the selected events. 


\subsubsection{Damage data}

The 'Consorcio de Compensación de Seguros' (CCS) covers all insurance compensations for natural hazards in Spain. CCS supplied a database that includes insurance flood losses in the Pamplona metropolitan area in the period 1996-2018. The data are classified by sectors into households, commercial sector and stores, industrial sector, offices, infrastructure and vehicles. In addition, the CCS database supplies the postal code where each claim was compensated.

The consumer price index (CPI) in the period 19962018 was considered to update flood losses to the year 2019. In addition, $86 \%$ of households are insured in the Navarre Region. Therefore, insurance losses supplied by CCS will correspond to the $86 \%$ of flood damages estimated by the damage model.

\subsubsection{Selected flood events}

Seven flood events were selected with both 15-min streamflow and damage data available (Table 1).

\begin{tabular}{|c|c|c|}
\hline Date & $\begin{array}{c}\text { Peak discharge } \\
\left(\mathrm{m}^{3} / \mathrm{s}\right)\end{array}$ & $\begin{array}{c}\text { Total flood } \\
\text { damages }^{2}(\mathrm{k} €)\end{array}$ \\
\hline 12 February 2009 & 413 & 2,413 \\
\hline 15 January 2013 & 464 & 3,242 \\
\hline 9 June 2013 & 508 & 13,066 \\
\hline 30 January 2015 & 359 & 304 \\
\hline 24 February 2015 & 434 & 555 \\
\hline 16 January 2017 & 351 & 132 \\
\hline 12 April 2018 & 388 & 290 \\
\hline
\end{tabular}

Table 1. Flood events selected in the Pamplona metropolitan area. ${ }^{1}$ Values obtained from the data supplied by the 'SAIH' real-time system of the Ebro River Basin Authority. ${ }^{2}$ Values obtained from the data supplied by CCS updated to 2019 .

\subsubsection{Additional data}

The regional Government of Navarre supplied the delineation of the flood extension for the real flood event of 9 June 2013. Such a flood extension has been used in the study to calibrate the 2-D hydrodynamic model.

The Spanish National Geographic Institute (IGN, in Spanish) supplied a 1-meter digital terrain model (DTM) for the flood prone area of Pamplona. Such a DTM was modified to include building heights, in order to consider the obstructions in water flow caused by buildings. Building height and footprint shapefiles were supplied by the Territorial Information System of the Navarre Region (SITNA, in Spanish).

Data about building occupancy were extracted from the database supplied by the Cadastre of the Navarre Region.
The database includes the occupancy and area of each urban unit (e.g., flats and houses) in alphanumeric format. However, the data about occupancy had to be aggregated by urban parcels, as they are the smaller units that are available in shapefile format to be placed and processed by Geographical Information System (GIS) tools.

Data about building occupancy were classified into 24 classes, following the Spanish recommendations extracted from the guidance for cost-benefit analyses required in flood mitigation measures (CEDEX, 2020). Such classes were households, storage rooms in households, garages, car parks, offices, shops, shopping centres, stores with no use, show businesses, bars and cafeterias, restaurants, hotels, service stations, industrial sector, storage rooms in the industrial sector, indoor sport centres, health facilities, education centres, religious buildings, outdoor sport centres and facilities and green areas, special buildings, service infrastructures, agricultural buildings and others.

The Cadastre of the Navarre Region also supplied the assessment of property rateable values per building use and zone in each municipality.

\section{Methodology}

In the Pamplona metropolitan area, the empirical damage function consists of a reduced set of seven points, as there are only seven events with information about both flood hydrographs and damages (Figure 3). No information is available for floods with peak discharges higher than $508 \mathrm{~m}^{3} / \mathrm{s}$ that corresponds to a return period of $5-10$ years.

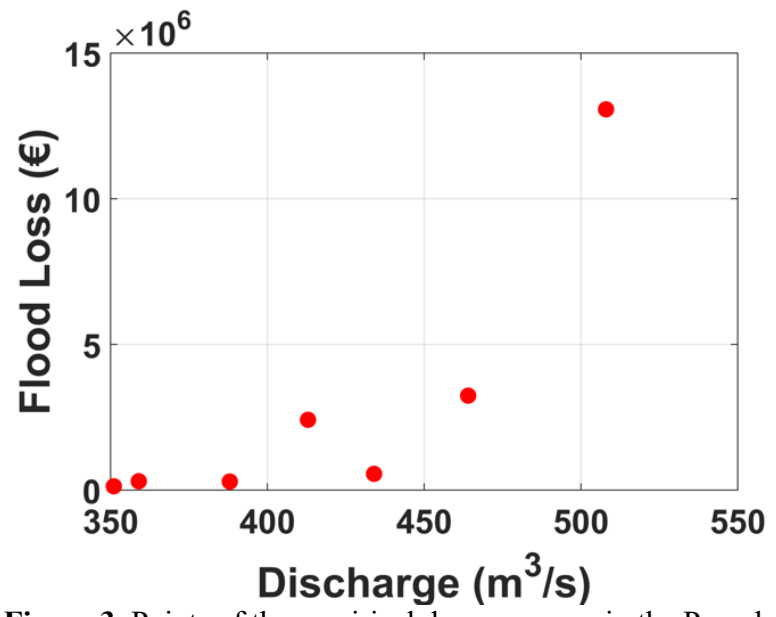

Figure 3. Points of the empirical damage curve in the Pamplona metropolitan area with the data included in Table 1.

However, a damage function that includes flood losses for larger events is needed to cover the complete probability distribution of peak discharges, required for calculating EAD in the metropolitan area of Pamplona. Therefore, the methodology proposed in this section aims to develop a damage model to extend the dischargedamage function in the metropolitan area of Pamplona. Flood damages in real events supplied by CCS are used to calibrate such a damage model.

For the set of seven flood events that were selected (Table 1), the 2D IBER hydrodynamic model is used to estimate the spatial distribution of water depths in the 
flooded area and, more specifically, the mean water depth in each inundated building.

First, the 2D IBER hydrodynamic model is calibrated with the flood hydrographs and the real flood extension available for the 9 June 2013 event. Second, spatial distributions of water depths for the set of seven flood events are obtained by using the calibrated 2D IBER hydrodynamic model. Third, mean water depths in each building are obtained by using GIS tools. Fourth, a damage model is developed, estimating relative flood damages in each urban parcel by using a set of predefined depthrelative damage functions in terms of building occupancy. Fifth, relative flood damages are transformed into absolute flood damages with property rateable values. Sixth, the discharge-damage function is estimated and EAD is calculated in the Pamplona metropolitan area.

\subsection{Hydrodynamic model}

Flood extensions and water depths for the seven selected events are determined through numerical simulations by using the openly available IBER code (Cea et al., 2007; Bladé et al., 2014; Cueto-Felgueoso et al., 2019). Such a code solves the depth-averaged shallow water equations using a finite volume scheme. The conservation of mass equation is given by Eq. 1. The momentum balance equations in conservative form with source terms are given by Eq. 2 and 3 .

$$
\begin{gathered}
\frac{\partial h}{\partial t}+\frac{\partial h U_{x}}{\partial x}+\frac{\partial h U_{y}}{\partial y}=0, \\
\frac{\partial h U_{x}}{\partial t}+\frac{\partial}{\partial x}\left(h U_{x}^{2}\right)+\frac{\partial}{\partial y}\left(h U_{x} U_{y}\right) \\
=-g h \frac{\partial z_{b}}{\partial x}-\frac{\tau_{b, x}}{\rho} \\
\frac{\partial h U_{y}}{\partial t}+\frac{\partial}{\partial x}\left(h U_{x}^{2}\right)+\frac{\partial}{\partial y}\left(h U_{y} U_{x}\right) \\
=-g h \frac{\partial z_{b}}{\partial x}-\frac{\tau_{b, y}}{\rho} .
\end{gathered}
$$

where, $h$ is the water depth, $U_{i}$ is the depth average velocity along the $i$ th direction, $\rho$ is the density of water, $z_{b}$ is the channel-bottom height, $g$ is the acceleration of gravity, and $\tau_{b, i}$ is the bed friction term in the $i$ th direction. Molecular and eddy viscosities, wind traction, as well as Coriolis acceleration are neglected. The bed friction terms, $\tau_{b, i}$, are given by Eq. 4 .

$$
\tau_{b, i}=\rho g h \frac{n^{2} U_{i}^{2}}{h^{4 / 3}}=0 .
$$

where $n$ is the Manning's roughness coefficient.

The equations are solved by using a first-order finite volume scheme based on the monotonic upwind scheme for conservation laws (MUSCL) (Alcrudo and GarcíaNavarro, 1993).

\subsection{IBER model calibration}

The hydrodynamic model parameters were calibrated with the real flood extension for the flood event of 9 June 2013, supplied by the regional Government of Navarre (Figures 4 and 5). The greatest flow obstructions in the River Arga caused by old bridges were considered in the model. The spatial distribution of roughness coefficient values was estimated by using land uses supplied by the CORINE Land Cover. Roughness coefficient values in the channel were calibrated to fit the IBER outputs to the real flood extension in the 9 June 2013 flood event.

The 15-min flood hydrographs recorded in three gauging sites in the Arga, Ulzama and Elorz Rivers for the seven flood events were used as input data. The rating curve at the gauging site located in the Arga River downstream the city of Pamplona was used as a boundary condition for backwater calculations.

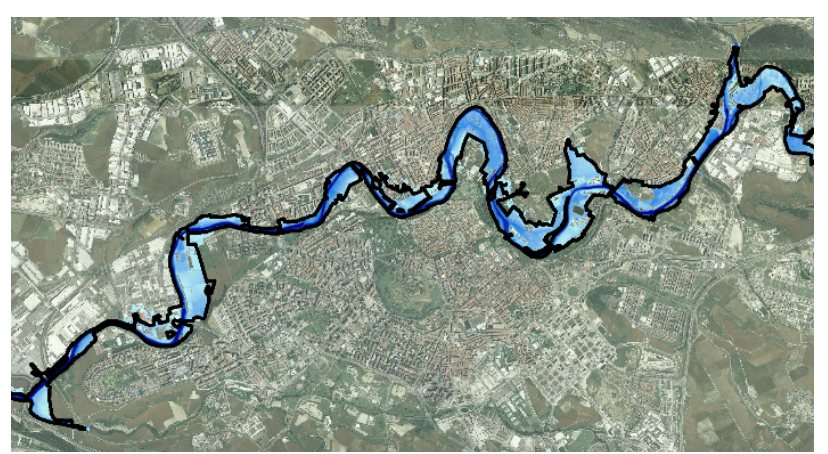

Figure 4. Results of the calibration of the IBER model. The black line represents the real flood extension. The IBER output is shown in blue colours.

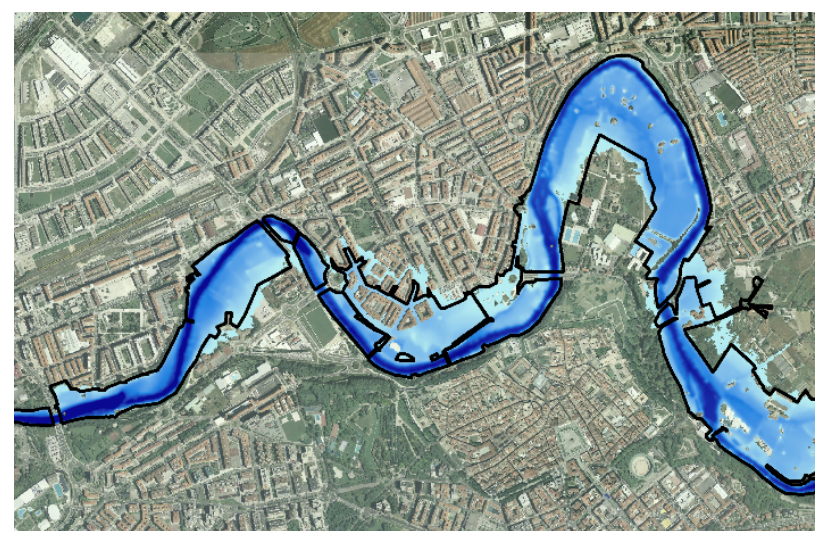

Figure 5. Detail of the results of the calibration of the IBER model in the Pamplona municipality. The black line represents the real flood extension. The IBER output is shown in blue colours.

\subsection{Damage model}

Mean water depths in each building located in the flooded area were obtained by processing the output of the 2D IBER hydrodynamic model with a GIS tool. Buffer polygons with a distance of 10 meters were created outside building footprints, in order to calculate mean water depths around each building. Mean water depths in parcels were obtained by weighting mean water depths in the buildings contained in each parcel. 
A set of predefined depth-relative damage functions in terms of building use were applied to transform mean water depths into relative damages in each parcel. Such relative damage functions were extracted from the recommendations of the Spanish guideline for conducting cost-benefit analyses for flood mitigation measures (CEDEX, 2020).

Building occupancy in ground floors and basements were considered, aggregating occupancy areas per uses and parcels. Basements properties were considered to be flooded completely for water depths larger than $1.2 \mathrm{~m}$. Ground floors were considered to begin their inundation for water depths larger than $10 \mathrm{~cm}$. Relative damages in each parcel were quantified per building use. The 24 building use classes described in Section 2.2.4 were considered.

The expected relative structural damages in buildings in each parcel are calculated by using such flow depthrelative damage functions. In addition, flood damages in building contents are calculated as a fraction of the relative structural damages that depends on the building use, following CEDEX (2020). For instance, industrial buildings will have higher content damages than residential buildings.

Finally, relative damages are transformed into absolute damages by using the property rateable values. Absolute damages were quantified in each parcel per building use. The absolute damage results were aggregated by postal codes and municipalities, in order to compare them with the real flood damages supplied by CCS.

\subsection{Discharge-damage function}

The discharge-damage function in the metropolitan area of Pamplona was obtained by coupling the outputs of the $2 \mathrm{D}$ hydrodinamical model for a set of synthetic flood events to the damage model.

The gauging station located in the River Arga in Pamplona has streamflow data in the period 2008-2019. Such a period is short for estimating a flood frequency curve. Therefore, the flood quantiles for a set of given return periods in the River Arga in Pamplona were obtained from CAUMAX that is a national scale study conducted in Spain previously (Jiménez-Álvarez et al., 2014).

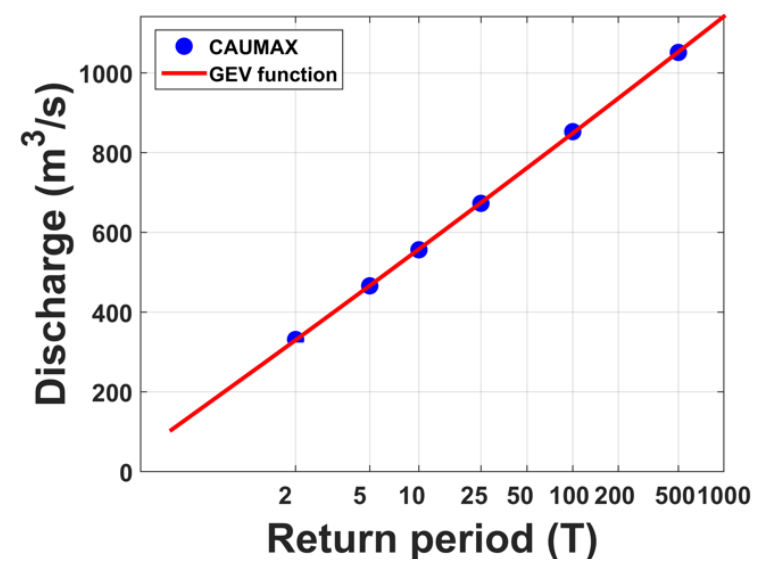

Figure 6. Flood frequency curve in the River Arga in Pamplona.
Figure 6 shows the flood frequency curve in the River Arga in Pamplona by fitting a GEV function with the flood quantiles supplied by CAUMAX. A set of peak discharges between $105 \mathrm{~m}^{3} / \mathrm{s}$ and $1141 \mathrm{~m}^{3} / \mathrm{s}$ were selected to cover the probability distribution, in order to obtain an accurate estimate of EAD.

A flood hydrograph was estimated for each peak discharge, considering the hydrograph shapes recorded in real past flood events. The synthetic flood events were simulated by using the calibrated IBER model, obtaining the spatial distribution of water depths.

\section{Results}

In this section, first, insurance flood loss data are processed to identify the areas and sectors that suffer the greatest losses. Second, the results of the damage model are analysed. Third, the discharge-damage function in the metropolitan area of Pamplona is obtained. Fourth, EAD is calculated in the metropolitan area of Pamplona.

\subsection{Insurance flood loss data in the metropolitan area of Pamplona}

CCS supplied the database of flood losses in the Pamplona metropolitan area in the period 1996-2018. Insurance flood losses do not include clean-up, evacuation, emergency service and disaster management costs.

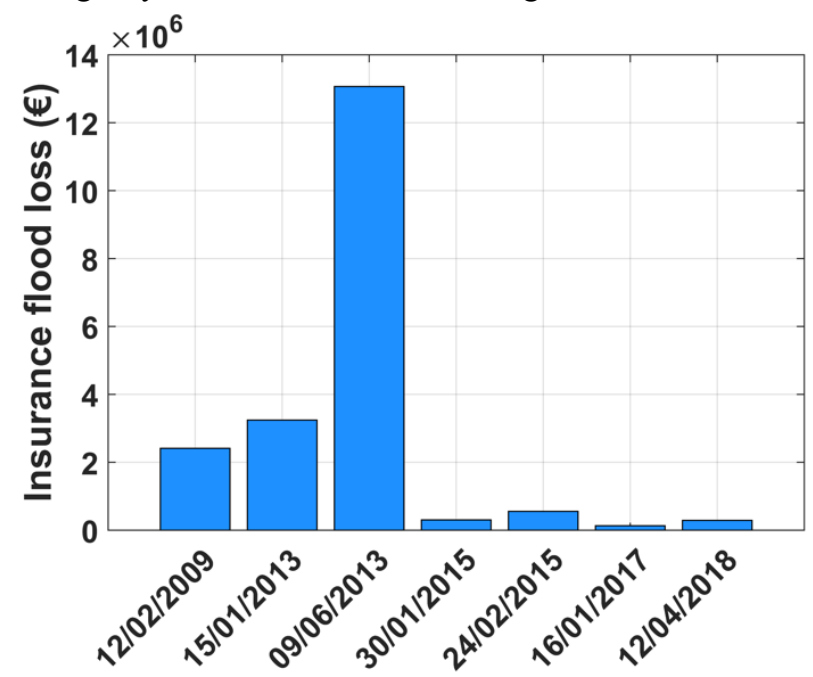

Figure 7. Flood losses in the seven flood events of Table 1 in the metropolitan area of Pamplona, obtained from the database supplied by CCS.

Figure 7 shows the insurance flood losses in the metropolitan area of Pamplona for the seven events considered as case studies (Table 1). The 9 June 2013 flood event caused the greatest flood damages with 13.1 M€. The 15 January 2013 event caused a flood loss of 3.2 M€ and the 12 February 2009 event $2.4 \mathrm{M} €$. The rest of flood events caused smaller losses lower than $1 \mathrm{M} €$.

Figure 8 shows insurance flood losses per sector in each flood event. Relative magnitudes vary depending on the flood event. In general, the commercial and residential sectors suffer the greatest losses. However, flood losses in infrastructure were the largest for the 15 January 2013 
event. In the 9 June 2013 flood event, damages in the industrial sector were comparable to the damages in the residential and commercial sectors.

In the 12 February 2009 event, the residential sector suffered the greatest losses with $1.1 \mathrm{M} €$, followed by the commercial sector with $0.82 \mathrm{M} €$. In the 15 January 2013 event, most of flood damages were caused by infrastructure with only one claim of $2.5 \mathrm{M} €$. Then, the commercial sector and households. In the 9 June 2013 event, households suffered the greatest flood damages with 4.6 M€. Then, the commercial sector with 4.1 M€ and the industrial sector with $3.3 \mathrm{M} €$.

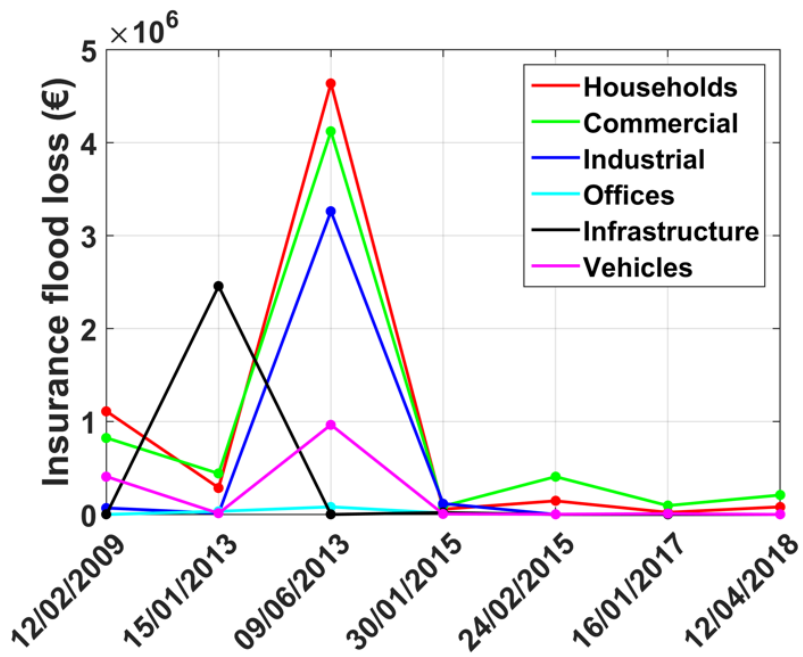

Figure 8. Insurance flood losses by sector in the seven flood events of Table 1 in the metropolitan area of Pamplona, obtained from the database supplied by CCS.

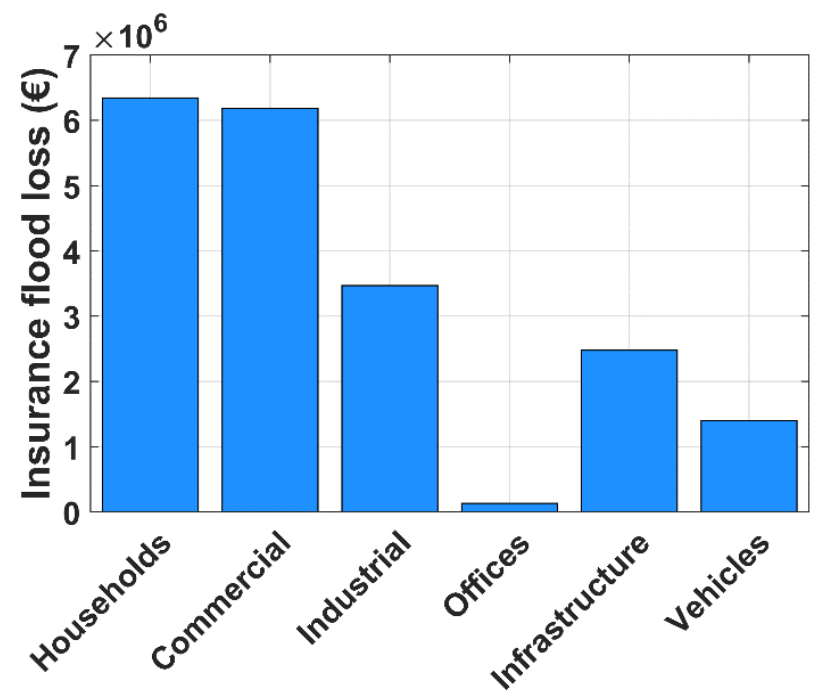

Figure 9. Insurance flood losses accumulated by sectors in the seven flood events of Table 1 in the metropolitan area of Pamplona, obtained from the database supplied by CCS.

Figure 9 shows the accumulated insurance flood losses in the seven flood events per sector. Residential and commercial sectors suffered the greatest losses with 6.3 M€ and 6.2 M€, respectively, followed by the industrial sector with $3.5 \mathrm{M} €$. Floods also caused a loss of 2.5 M€ in infrastructure, but it corresponds to only one claim in the 15 January 2013 event. Vehicles suffered
1.4 M€ losses. Offices show the smallest flood losses with $0.13 \mathrm{M} €$.

Figure 10 shows the accumulated insurance flood losses by municipalities in the seven flood events. Pamplona is the municipality that suffers the greatest losses with $13.3 \mathrm{M} €$. Villava is the second municipality with $3.96 \mathrm{M} €$. Third, Huarte with $1.46 \mathrm{M} €$. Fourth, Burlada with 1.25 M€. Fifth, Cendea with 0.04 M€.

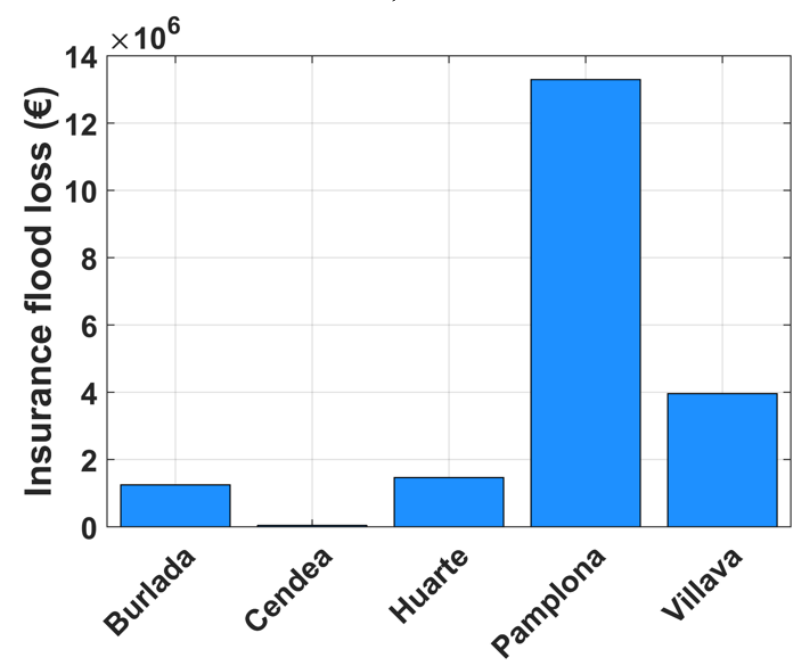

Figure 10. Accumulated insurance flood losses by municipalities in the seven flood events of Table 1. Data obtained from the database supplied by CCS.

Figure 11 shows insurance flood losses by municipalities and events. Pamplona is the municipality with the greatest losses in all the events. However, some changes are observed in Burlada, Huarte and Villava. While Burlada shoes the second greatest flood losses in the 2009 flood event, Villava is the second in the January and June 2013 flood events. Such a change could be caused by either new building constructions in Villava and Huarte or new flood mitigation measures that reduced flood risks in Burlada.

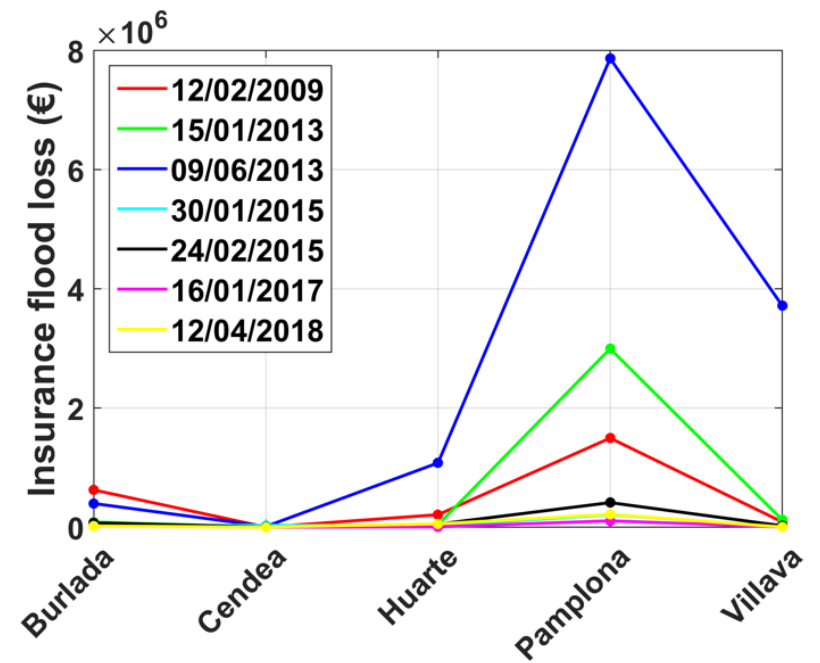

Figure 11. Insurance flood losses by municipalities and events, obtained from the database supplied by CCS.

Figure 12 shows the accumulated insurance flood losses by sector and municipality in the seven flood events. In Pamplona, the commercial sector suffers the greatest losses with 4.36 M€. The second sector is households with 
3.42 M€, followed by infrastructure with $2.46 \mathrm{M} €$, the industrial sector with 1.90 M€, vehicles with 1.03 M€ and offices with $0.12 \mathrm{M} €$.

In Villava, households shows the greatest losses with 2.01 M€, followed by the industrial sector with $0.89 \mathrm{M} €$ and the commercial sector with $0.71 \mathrm{M€}$.

In Huarte, the industrial sector has the greatest losses with $0.64 \mathrm{M} €$, followed by the residential sector with $0.51 \mathrm{M} €$ and the commercial sector with 0.29 M€.

In Burlada, the greatest losses are suffered by the commercial sector with $0.83 \mathrm{M} €$ and households with $0.39 \mathrm{M} €$.

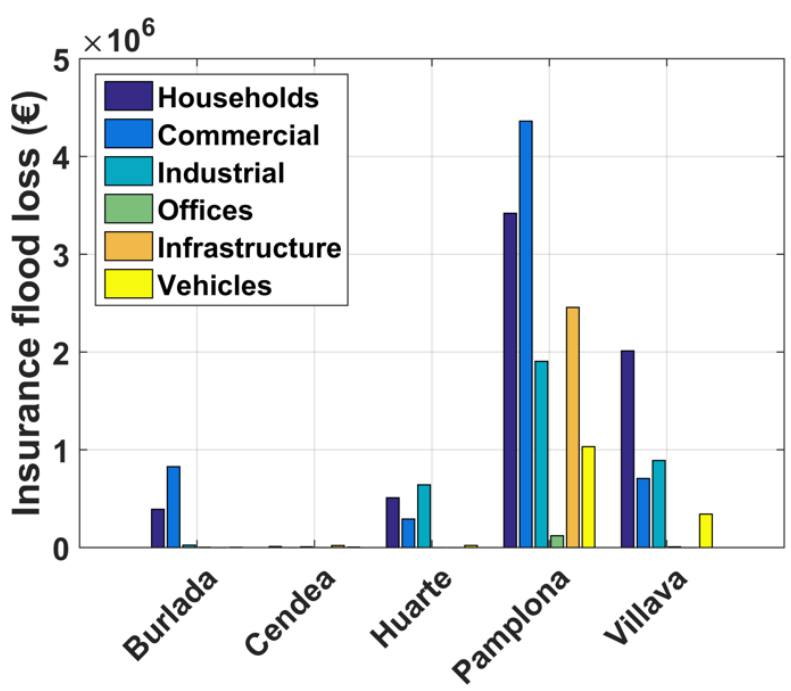

Figure 12. Insurance flood losses by municipality and sector accumulated in the seven flood events of Table 1. Data obtained from the database supplied by CCS.

The database supplied by CCS includes the postal code for each claim. Burlada, Cendea, Huarte and Villava are composed of a unique postal code. Therefore, a finer spatial resolution cannot be achieved in such municipalities. However, the results for the city of Pamplona can be distributed spatially in a set of 10 postal codes (Figure 13).

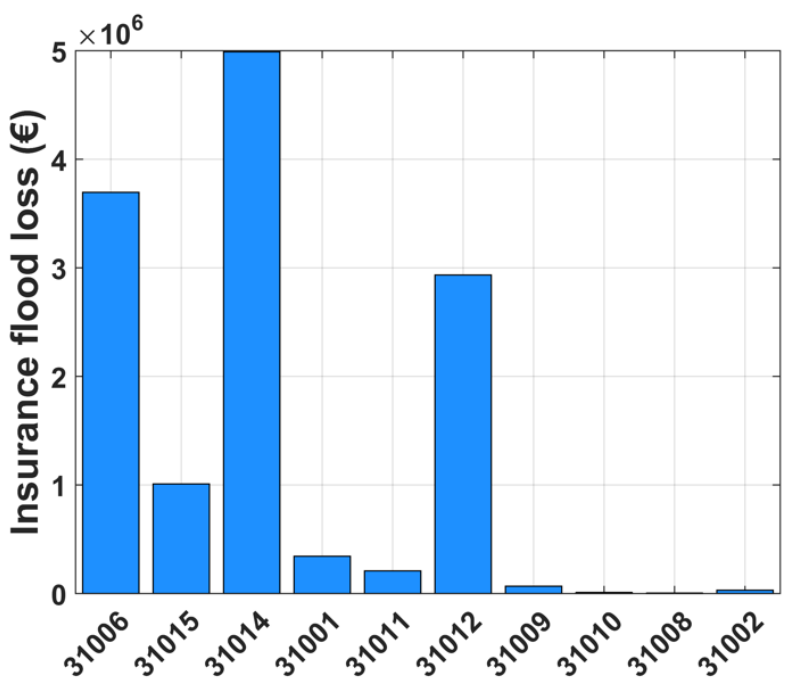

Figure 13. Insurance flood losses in Pamplona municipality by postal code. Data obtained from the database supplied by CCS.
Figure 13 shows insurance flood losses by postal code in the municipality of Pamplona. Most of losses are concentrated in four postal codes. The 31014 postal code shows the greatest losses with 4.99 M€. Such a postal code includes the Rochapea neighbourhood and the Aranzadi Meander (Figure 14). Second, the 31006 postal code with 3.70 M€, containing the area close to Burlada and a part of the river Elorz overbank (Figure 14). Third, the 31012 postal code with $2.93 \mathrm{M} €$, covering the western part of Pamplona and the Landaben industrial area (Figure 14). Fourth, the 31015 postal code with 1.01 M€, containing the Magdalena neighbourhood (Figure 14).

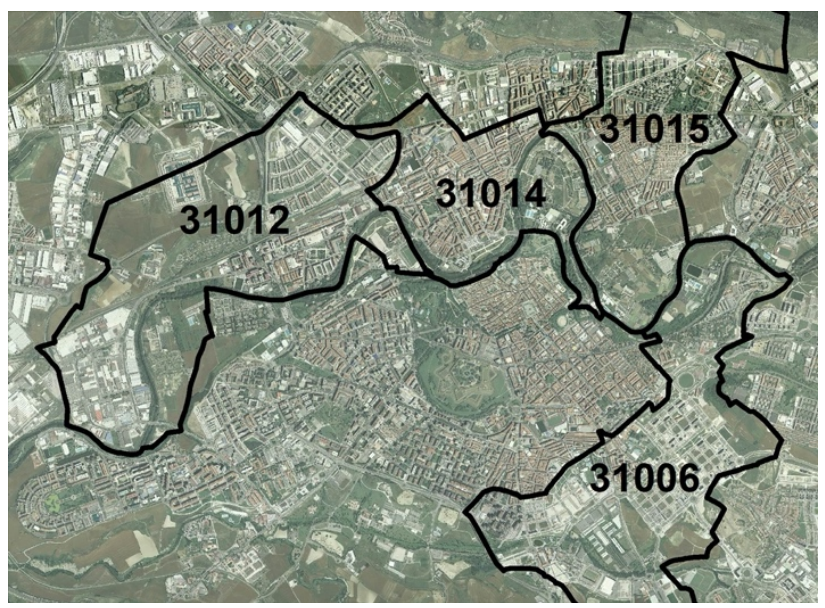

Figure 14. Postal codes with the greatest insurance flood losses in the city of Pamplona.

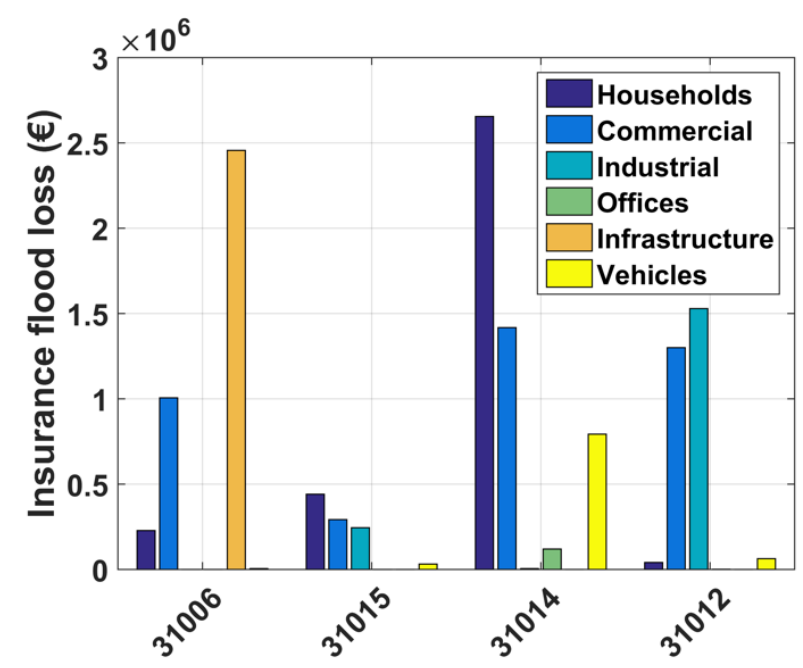

Figure 15. Insurance flood losses by sector in the four postal codes with the greatest losses in the city of Pamplona, obtained from the database supplied by CCS.

Figure 15 shows the distribution of insurance flood losses by sector in the four postal codes with the greatest damages in Pamplona. In the 31006 postal code, losses are amplified by a claim of $2.46 \mathrm{M} €$ in infrastructure, though the commercial sector shows the greatest losses with $1.01 \mathrm{M} €$. In the 31015 postal code, the greatest losses are registered in the residential sector located in the Magdalena neighbourhood with $0.44 \mathrm{M} €$, followed by the commercial and industrial sectors with $0.29 \mathrm{M} €$ and $0.24 \mathrm{M} €$, respectively. In the 31014 postal code the greatest losses are also in the residential sector with 
2.66 M€, mainly in the Rochapea neighbourhood, followed by the commercial sector with $1.42 \mathrm{M} €$. In the 31012 postal code, the greatest losses are in the industrial and commercial sectors with 1.53 M€ and 1.30 M€, respectively, mainly in the Landaben industrial area.

\subsection{Results of the flood damage model}

The damage model has been applied to the seven flood events selected as case studies (Table 1). Mean water depths in each parcel were obtained from the hydrodynamic model outputs by using GIS tools. Such mean water depths are the flood damage model input data. The damage model supplies estimated flood losses in each parcel (Figure 16).

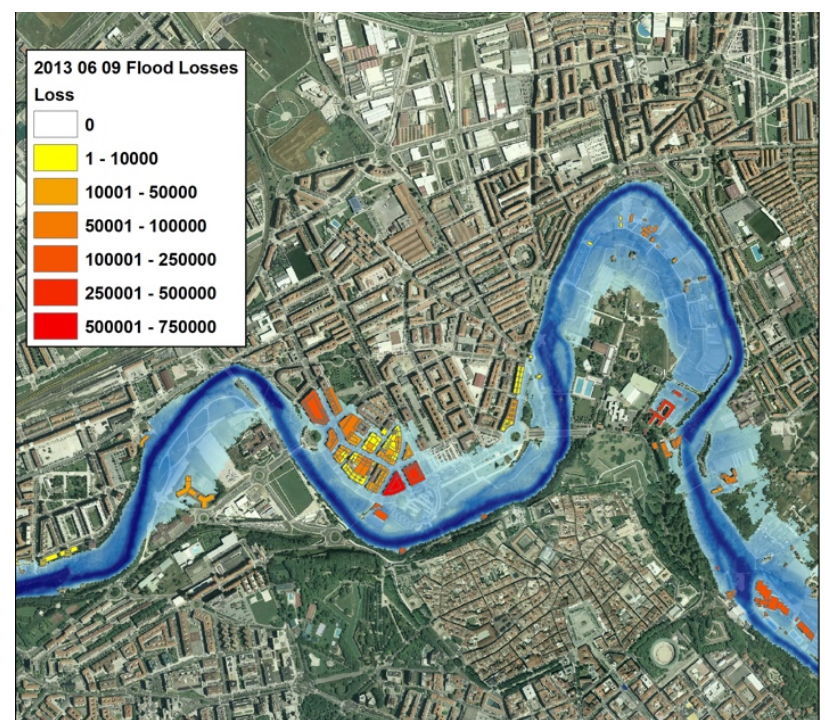

Figure 16. Results of the damage model in Euros in the postal code 31014 in the 9 June 2013 flood event.

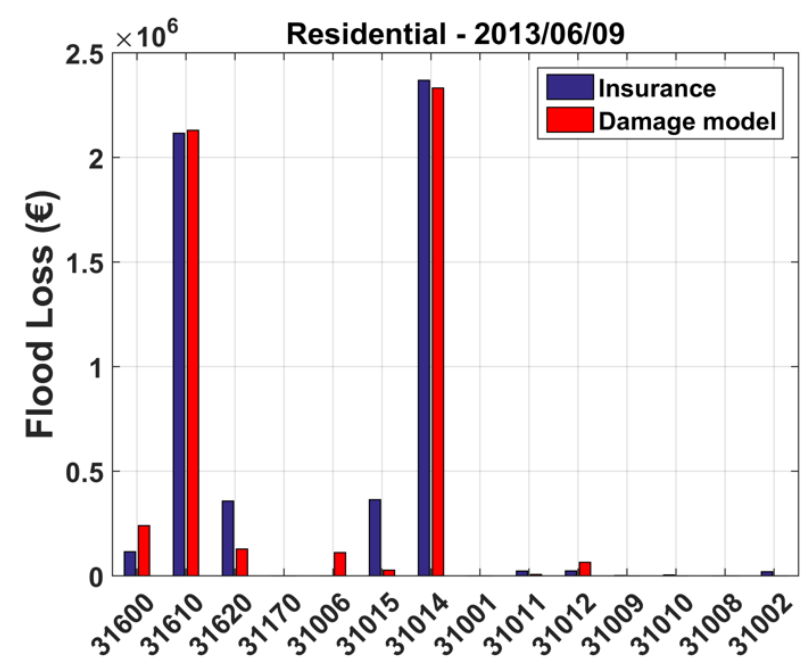

Figure 17. Comparison between the damage model and insurance flood losses supplied by CCS for the residential sector by postal codes.

The results per parcels are aggregated by postal codes, to compare the damage model with the insurance flood losses supplied by CCS. Insurance losses supplied by CCS correspond to the $86 \%$ of the flood damages estimated by the damage model. Therefore, insurance flood losses are increased to improve the comparison accuracy. The flood event of 9 June 2013 has been selected to show the results in this subsection.

Figure 17 shows the results for the residential sector. In the postal code 31620 that corresponds to Huarte, the damage model overestimates the results. In the postal code 31610 that contains the municipality of Villava, the damage model fits the observations perfectly. The postal codes 31600 (Magdalena neighbourhood) and 31015 (Burlada) have a boundary that crosses a residential zone in the flooded area. Consequently, the overestimation in the postal code 31600 compensates for the underestimation in the postal 31015 . Finally, in the postal code 31014 (Rochapea neighbourhood) the damage model underestimates slightly the results.

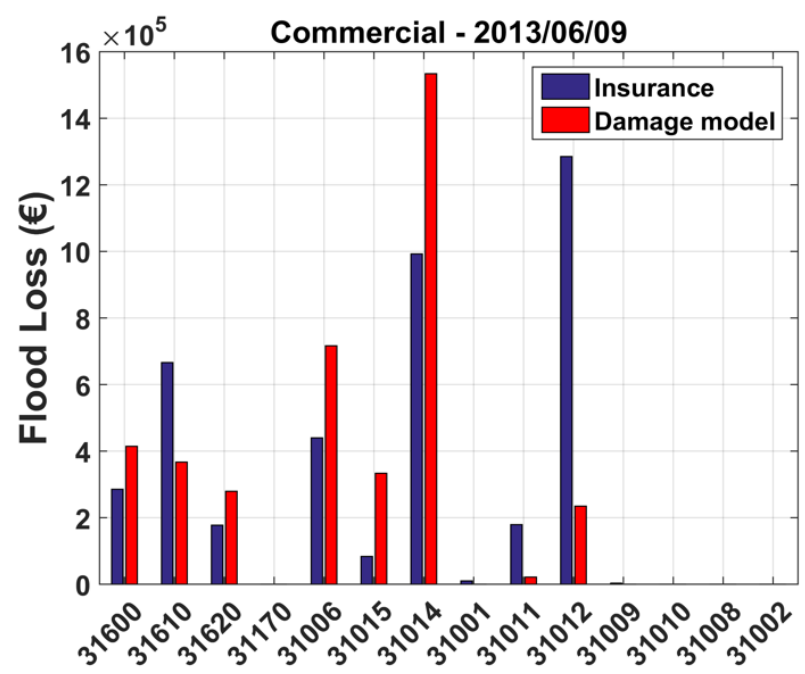

Figure 18. Comparison between the damage model and insurance flood losses supplied by CCS for the commercial sector by postal codes.

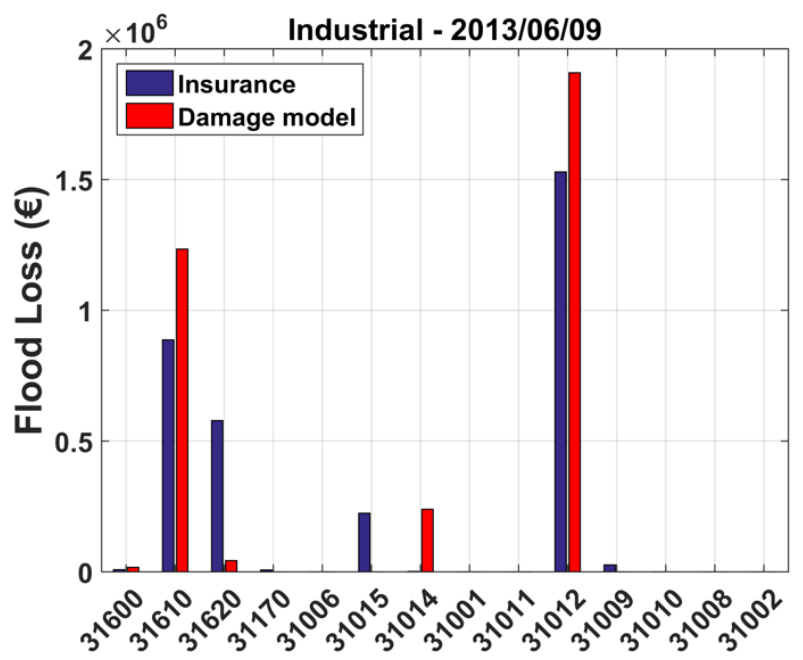

Figure 19. Comparison between the damage model and insurance flood losses supplied by CCS for the industrial sector by postal codes.

Figure 18 shows the results for the commercial sector. The damage model provides varying results depending on the postal code. The damage model overestimates the results in the postal codes 31620 (Huarte), 31600 (Burlada), 31015 (Magdalena neighbourhood) and 31014 
(Rochapea neighbourhood). However, the results are underestimated in the postal codes 31610 (Villava) and 31012 (Landaben industrial area). The largest differences are found in the postal codes 31610 and 31012, underestimating the insurance flood losses, as well as in the postal code 31014 , overestimating the losses. In the Landaben industrial area (postal code 31012), underestimated results could be caused by some parcels with industrial use that are actually occupied by commercial centres.

Figure 19 shows the results for the industrial sector. In the Landaben industrial area (postal code 31012) the results of the damage model are overestimated. As it was explained above, this can be caused by some parcels with industrial use, though occupied by commercial shops. In the postal codes 31620 (Huarte) and 31015 (Magdalena neighbourhood) the damage model underestimates the results.

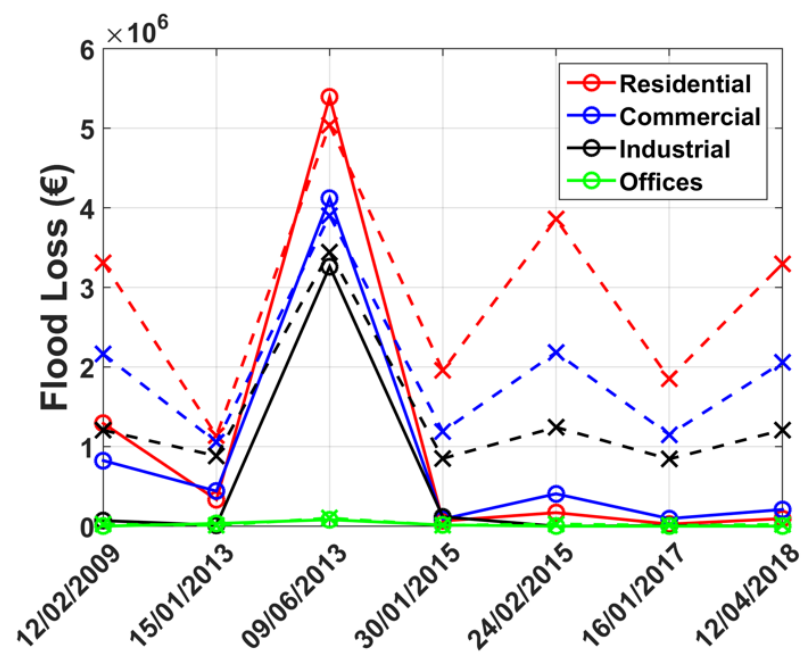

Figure 20. Comparison between the damage model and insurance flood losses supplied by CCS by flood events and sectors. Solid lines with circles represent the insurance flood losses and dashed lines with crosses the results of the damage model.

Figure 20 shows the comparison between the results of the damage model and the insurance flood losses recorded by CCS, by flood events and sectors. The results fit the insurance data for the flood event of 9 June 2013, mainly for the residential, commercial and industrial sectors. However, for the rest of events, the results supplied by the damage model overestimates flood damages, mainly for the residential sector.

Figure 21 shows the results by municipalities. The results of the damage model in Pamplona and Villava are overestimated in all the flood events, except the 9 June 2013 event.

Figure 22 shows the results of the damage model by flood events and sectors. The 9 June 2013 event generates the largest flood damages for the four sectors. Floods in the Pamplona metropolitan area cause the largest losses in the residential and commercial sectors. Flood losses in the industrial sector are smaller than in the residential and commercial sectors, though they are similar to them in the 9 June 2013 event.

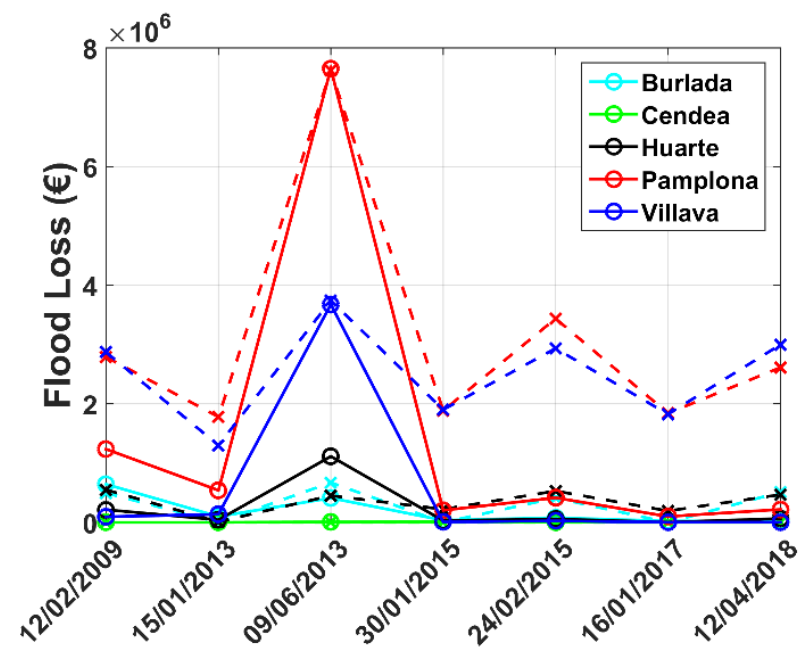

Figure 21. Comparison between the damage model and insurance flood losses supplied by CCS by municipalities and flood events. Solid lines with circles represent the insurance flood losses and dashed lines with crosses the results of the damage model.

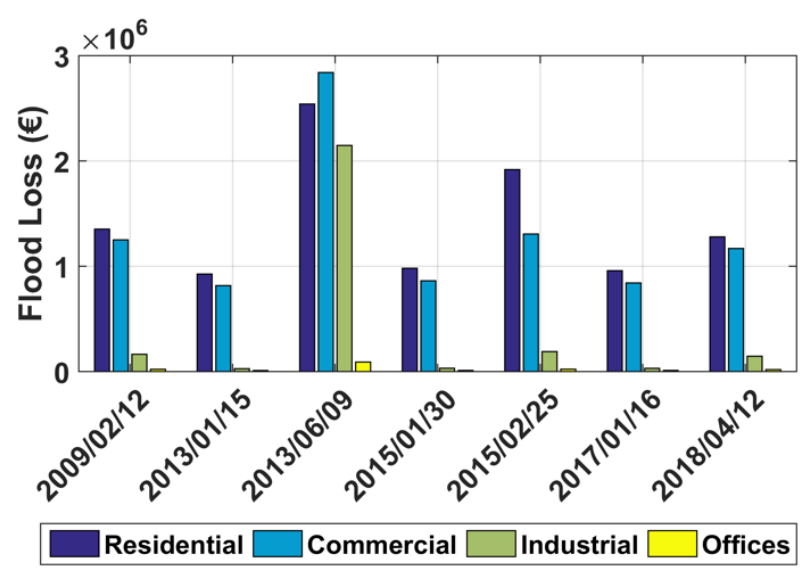

Figure 22. Results of the damage model by flood events and sectors.

\subsection{Discharge-damage function}

The discharge-damage function in the metropolitan area of Pamplona is obtained by coupling the hydrodynamic model to the damage model. A set of 24 synthetic flood events were simulated by the calibrated IBER model, considering peak discharges between $105 \mathrm{~m}^{3} / \mathrm{s}$ and $1141 \mathrm{~m}^{3} / \mathrm{s}$. Flood damages for each synthetic flood event were obtained by using the damage model with mean water depths in buildings located in each parcel.

Figure 23 shows the discharge-damage curve in the metropolitan area of Pamplona by sectors. The residential sector shows the highest damages for peak discharges higher than $300 \mathrm{~m}^{3} / \mathrm{s}$. For peak discharges between 300 and $800 \mathrm{~m}^{3} / \mathrm{s}$, commercial and industrial sectors have similar damage magnitudes. However, for peak discharges higher than $800 \mathrm{~m}^{3} / \mathrm{s}$, flood damages in the industrial sector are larger than in the commercial sector. Damages in offices could be neglected in the metropolitan area of Pamplona, as their magnitude is much smaller than the other sectors. 


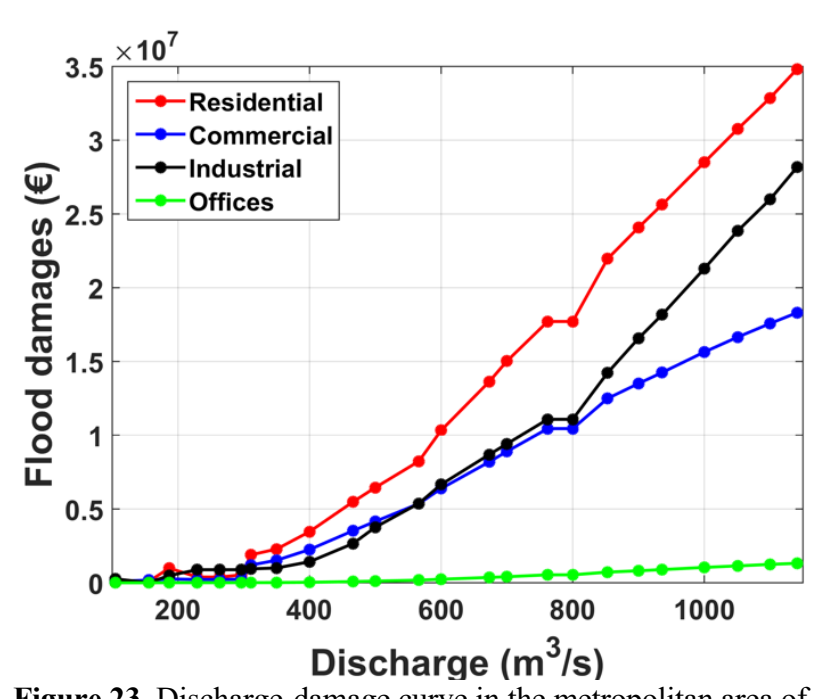

Figure 23. Discharge-damage curve in the metropolitan area of Pamplona by sectors.

\subsection{Annual expected damage}

Finally, the annual expected damage is obtained in the Pamplona metropolitan area by integrating the damageprobability curve (Figure 24), obtaining 7.75 M€. The spatial distribution of EAD was obtained by buildings contained in each parcel (Figure 25).

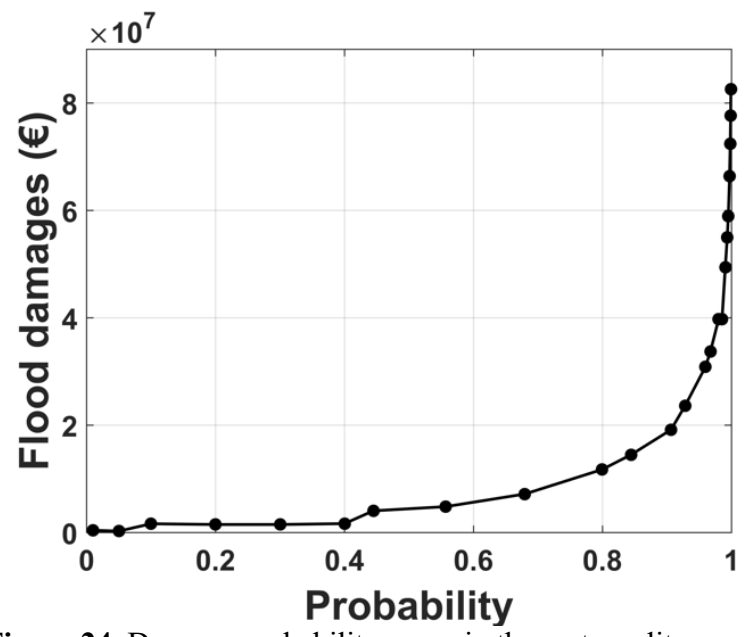

Figure 24. Damage-probability curve in the metropolitan area of Pamplona. The $\mathrm{x}$ axis shows the non-exceedance probability.

By sectors, the residential sector shows the largest EAD with $3.44 \mathrm{M} €$. The commercial and industrial sectors have a similar EAD with $2.12 \mathrm{M} €$ and $2.13 \mathrm{M} €$, respectively. Offices contribute with an EAD of 0.07 M€ (Figure 26).

By municipalities, Pamplona has the largest EAD with $3.98 \mathrm{M} €$, followed by Villava with 3.07 M€. In Pamplona, the commercial sector has an EAD of $1.45 \mathrm{M} €$, the residential sector 1.40 $\mathrm{M} €$ and the industrial sector 1.08 M€ (Figure 27). In Villava, the residential sector shows the largest EAD with $1.75 \mathrm{M} €$, followed by the industrial sector with $1.08 \mathrm{M} €$. The commercial sector has an EAD of 0.29 M€.

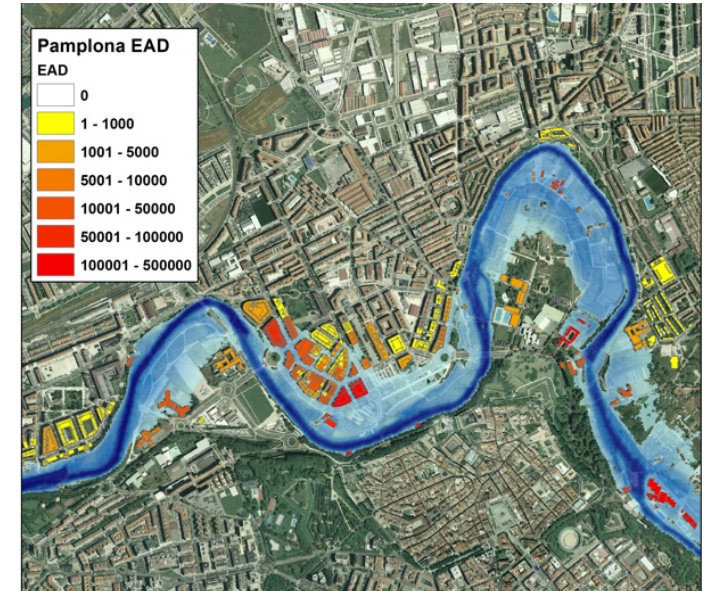

Figure 25. Detail of the spatial distribution of the expected annual damage in Euros in the metropolitan area of Pamplona by parcels.

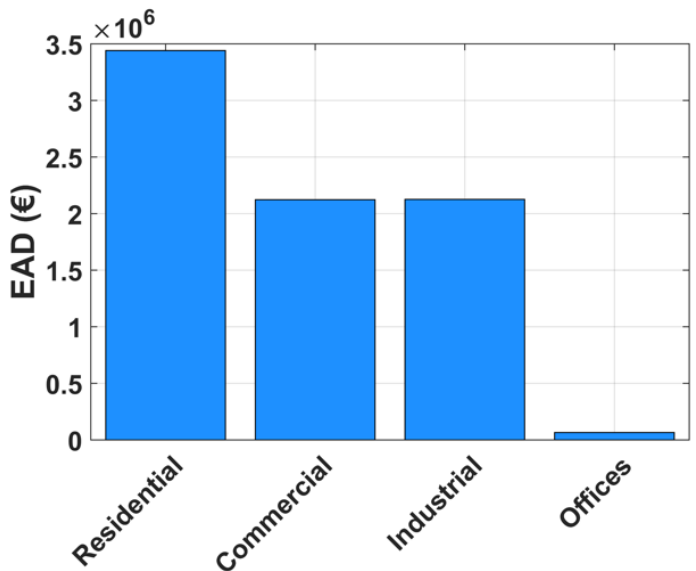

Figure 26. EAD in the Pamplona metropolitan are by sectors.

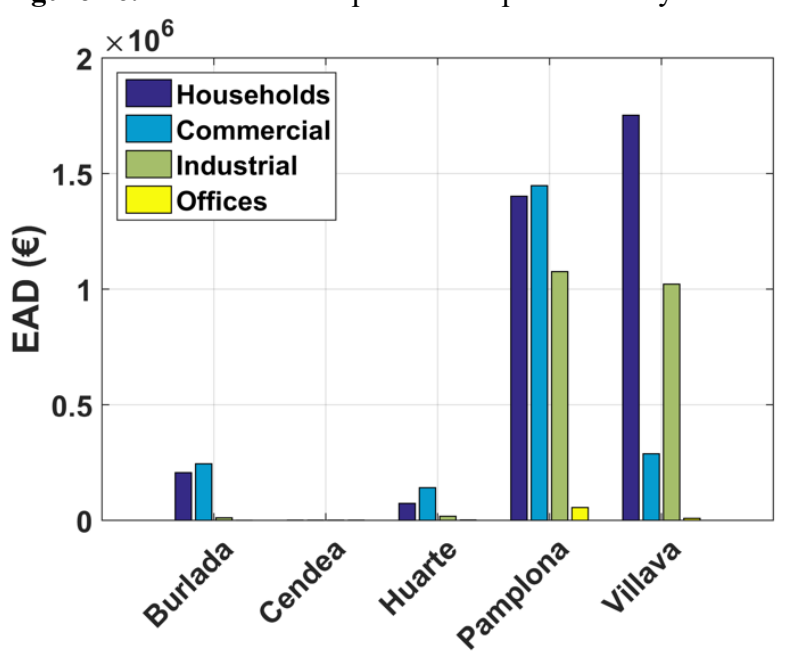

Figure 27. EAD in the Pamplona metropolitan are by municipalities and sectors.

\section{Discussion}

The results of the damage model present a set of limitations. The regional Cadastre of Navarre provides a detailed information of building occupancy in alphanumeric format by urban units, such as flats and stores. However, such urban units cannot be placed, as there is no GIS information available about them. Therefore, the cadastre information was aggregated by 
parcels, as they are the smallest urban unit that can be placed by using GIS tools. Such aggregation reduces the resolution of the results, as the mean water depth in all the buildings that are contained in each parcel has to be considered. Nevertheless, the real areas occupied in each parcel by building uses and floors were considered.

The insurance flood loss data only include one large flood event (9 June 2013) in the period with streamflow data in the River Arga in Pamplona. The rest of flood events are smaller and cause reduced flood damages. Consequently, the empirical damage function only includes one point with important flood damages. Therefore, both the hydrodynamic and damage models could be calibrated with only one event.

The results presented in this paper do not include cleanup, evacuation, emergency service and disaster management costs.

Finally, the damage model overestimates damages for small flood events. This can be attributed to new mitigation measures that are not included in the DTM or that are not well captured by the hydrodynamic model, flooding overbanks when they should not be inundated.

\section{Conclusions}

In this paper, insurance flood losses in the metropolitan area of Pamplona supplied by CCS have been processed, identifying the areas and sectors that suffer the largest damages in a set of past flood events. In addition, a damage model has been developed. The results of the damage model in the metropolitan area of Pamplona have been presented. The discharge-damage function and the expected annual damage in the metropolitan area of Pamplona have been estimated.

The 2-D IBER hydrodynamic model was used to obtain the spatial distribution of water depths in the flooded area for the seven events considered. The model was calibrated for the real event of 9 June 2013. Mean water depths in the buildings contained in each parcel placed in the flooded area were obtained by using GIS tools. Areas occupied by each building use in parcels were aggregated by floors. 24 building uses were considered.

The largest flood losses were caused by the 9 June 2013 event with $13.1 \mathrm{M} €$. The 15 January 2013 event recorded 3.2 $\mathrm{M} €$ and the 12 February 2009 event 2.4 M€. Accumulating insurance flood losses in the seven events, residential and commercial sectors suffered the greatest flood losses with 6.3 M€ and 6.2 M€, respectively, followed by the industrial sector with $3.5 \mathrm{M} €$.

By municipalities, Pamplona suffered the largest flood losses in the seven events with 13.3 M€, followed by Villava with $3.96 \mathrm{M} €$. In Pamplona, the commercial sector presented the greatest flood losses with $4.36 \mathrm{M} €$, followed by the residential sector with $3.42 \mathrm{M} €$. In Villava, the residential sector shows the greatest flood losses with 2.01 M€, followed by the industrial sector with $0.89 \mathrm{M} €$.

In Pamplona, most of flood losses are concentrated in three postal codes: 31014 with 4.99 M€ (Rochapea neighbourhood), 31012 with $2.93 \mathrm{M} €$ (Landaben industrial area) and 31015 with 1.01 M€ (Magdalena neighbourhood). While in the postal codes 31014 and
31015 the largest flood losses are recorded in the residential sector, in the postal code 31012 industrial and commercial sectors suffer the greatest losses.

The damage model obtains a good fit for the residential sector for the flood event of 9 June 2013, in terms of total damages, as well as partial damages by postal codes. However, errors in the commercial and industrial sectors are higher by postal codes, though results are compensated at larger scales. For the rest of flood events, the results are overestimated for all the sectors in the five municipalities.

The damage model has been used to obtain the discharge-damage function in the metropolitan area of Pamplona. The residential sector shows the highest damages for peak discharges higher than $300 \mathrm{~m}^{3} / \mathrm{s}$. For peak discharges higher than $800 \mathrm{~m}^{3} / \mathrm{s}$, flood damages in the industrial sector are larger than in the commercial sector. Flood damages in offices are much smaller than in the other three sectors.

Finally, the expected annual damage was obtained spatially distributed by parcels. The expected annual damage was calculated in the Pamplona metropolitan area by integrating the damage-probability curve, obtaining $7.75 \mathrm{M}$. The residential sector shows the largest EAD with 3.44 M€. By municipalities, Pamplona has the largest EAD with $3.98 \mathrm{M} €$, followed by Villava with 3.07 M€.

Summarising, the analysis of insurance flood losses has identified the areas and sectors that suffer the highest flood damages in the metropolitan area of Pamplona. In addition, the damage model developed in this paper can be applied to flood risk assessment studies in the metropolitan area of Pamplona, more specifically to assess the benefits of flood mitigation measures in terms of flood damage reduction.

\section{Acknowledgments}

This work was supported by the EIT Climate-KIC project "SAFERPLACES - Improved assessment of pluvial, fluvial and coastal flood hazards and risks in European cities as a mean to build safer and resilient communities".

The authors acknowledge the 'Consorcio de Compensación de Seguros' for providing insurance data about flood damages, the SAIH System of the Ebro River Basin Authority and the Spanish Centre of Hydrographic Studies of CEDEX for providing streamflow data, the Regional Government of Navarre for providing the real flood extension for the flood event of 9 June 2013, and the Regional Cadastre of Navarre and SITNA for providing cadastre information and GIS shapefiles in the study area.

\section{References}

1. Alcrudo, A., P.A. García-Navarro (1993) High Resolution Godunov-Type Scheme in Finite Volumes for the 2D Shallow Water Equations. International Journal for Numerical Methods in Fluids 16: 489-505. doi: 10.1002/fld.1650160604

2. Arnell, N.W. (1989). Expected Annual Damages and Uncertainties in Flood Frequency Estimation. Journal of Water Resources Planning and Management 
115(1): $\quad 94-107 . \quad$ doi: $\quad 10.1061 /(A S C E) 0733-$ 9496(1989)115:1(94)

3. Bladé, E., L. Cea, G. Corestein, E. Escolano, J. Puertas, E. Vázquez-Cendón, J. Dolz, A. Coll, (2014) Iber: herramienta de simulación numérica del flujo en ríos. Revista Internacional de Métodos Numéricos para Cálculo y Diseño en Ingeniería 483(30): 1-10. doi: 10.1016/j.rimni.2012.07.004

4. Budiyono, Y., J.C.J.H. Aerts, D. Tollenaar and P.J. Ward (2016) River flood risk in Jakarta under scenarios of future change. Natural Hazards and Earth System Sciences 16: 757-774. doi: 10.5194/nhess-16-757-2016.

5. Carisi, F., K. Schröter, A. Domeneghetti, H. Kreibich, and A. Castellarin (2018). Development and assessment of uni- and multivariable flood loss models for Emilia-Romagna (Italy). Natural Hazards and Earth System Sciences 18: 2057-2079. doi: 10.5194/nhess-18-2057-2018.

6. Cea, L., J. Puertas, M.E. Vázquez-Cendón (2007) Depth Averaged Modelling of Turbulent Shallow Water Flow with Wet-Dry Fronts. Archives of Computational Methods in Engineering 14: 303-341. doi: 10.1007/s11831-007-9009-3

7. CEDEX (2020). Guía metodológica para el análisis coste-beneficio de actuaciones estructurales de defensa frente a inundaciones. Centro de Estudios Hidrográficos del Centro de Estudios y Experimentación de Obras Públicas, Madrid, Spain. Draft version (in Spanish).

8. Cueto-Felgueoso, L, D. Santillán, J.H. GarcíaPalacios, L. Garrote (2019). Comparison between 2D Shallow-Water Simulations and Energy-Momentum Computations for Transcritical Flow Past Channel Contractions. Water 11(7): 1476. doi: 10.3390/w11071476.

9. Gerl, T., H. Kreibich, G. Franco, D. Marechal and K. Schröter (2016). A Review of Flood Loss Models as Basis for Harmonization and Benchmarking. PLoS ONE 11(7): e0159791. doi: 10.1371/journal.pone.0159791.

10. Huizinga, J., H. De Moel and W. Szewczyk (2017). Global flood depth-damage functions: Methodology and the database with guidelines. Publications Office of the European Union, JRC105688, Luxembourg. doi: $\quad 10.2760 / 16510$

11. Jiménez-Álvarez, A., C. García-Montañés, L. Mediero, L. Incio and J. Garrote-Revilla (2014). Bases metodológicas del mapa de caudales máximos de las cuencas intercomunitarias. Centro de Estudios y Experimentación de Obras Públicas, Madrid, Spain, 96 pp. (In Spanish).

12. Kind, J. (2014). Efficient flood protection standards for the Netherlands. Journal of Flood Risk Management 7: 103-117. doi:10.1111/jfr3.12026

13. te Linde, A.H., P. Bubeck, J.E.C. Dekkers, H. de Moel and J.C.J.H. Aerts (2011) Future flood risk estimates along the river Rhine. Natural Hazards Earth System Sciences 11: 459-473. doi: 10.5194/nhess-11-4592011.

14. Merz, B., H. Kreibich, R. Schwarze and A. Thieken (2010). Review article "Assessment of economic flood damage". Natural Hazards and Earth System Sciences, 10: 1697-1724. Doi: 10.5194/nhess-101697-2010.

15. Meyer, V., S. Priest and C. Kuhlicke (2012) Economic evaluation of structural and non-structural flood risk management measures: examples from the Mulde River. Natural Hazards 62: 301-324. doi: 10.1007/s11069-011-9997-z

16. de Moel, H. and J.C.J.H. Aerts (2011). Effect of uncertainty in land use, damage models and inundation depth on flood damage estimates. Natural Hazards 58: 407-425. doi: 10.1007/s11069-0109675-6

17. Paprotny, D., H. Kreibich, O. Morales-Nápoles, P. Terefenko and K. Schröter (2020a). Estimating exposure of residential assets to natural hazards in Europe using open data. Natural Hazards and Earth System Sciences 20: 323-343. doi: 10.5194/nhess-20323-2020.

18. Paprotny, D., K. Schröter, S. Bagli, A. Castellarin, A.H. Essenfelder, P. Mazzoli, L. Mediero, O. Morales-Napoles, J. Mysiak and H. Kreibich (2020b). Assessing direct flood damages using open data in diverse urban environments. 4th European Conference on Flood Risk Management, Budapest, Hungary, submitted.

19. Pistrika, A., G. Tsakiris, and I. Nalbantis (2014). Flood Depth-Damage Functions for Built Environment. Environmental Processes 1: 553-572. doi: $10.1007 / \mathrm{s} 40710-014-0038-2$

20. Rose, A. (2004). Economic Principles, Issues, and Research Priorities in Natural Hazard Loss Estimation. In: Okuyama Y. and S.E. Chang (eds). Modeling the Spatial Economic Impacts of Natural Hazards. Advances in Spatial Science. Springer, Heidelberg, pp. 13-36. doi: 10.1007/978-3-54024787-6_2

21. Schinke, R., A. Kaidel, S. Golz, T. Naumann, J.S. López-Gutiérrez and S. Garvin (2016). Analysing the Effects of Flood-Resilience Technologies in Urban Areas Using a Synthetic Model Approach. ISPRS International Journal of Geo-Information: 5 (11): 202. doi: 10.3390/ijgi5110202

22. Scorzini, A. and E. Frank (2017). Flood damage curves: new insights from Italy. Journal of Flood Risk Management 10: 381-392. doi: 10.1111/jfr3.12163

23. Smith, D.I. (1994). Flood damage estimation - A review of urban stage-damage curves and loss functions. Water $S A 20$ (3): 231-238.

24. Stedinger, J.R. (1997). Expected Probability and Annual Damage Estimators. Journal of Water Resources Planning and Management 123(2): 125135. doi:/10.1061/(ASCE)07339496(1997)123:2(125).

25. ten Veldhuis, J. (2011) How the choice of flood damage metrics influences urban flood risk assessment. Journal of Flood Risk Management 4: 281-287. doi:10.1111/j.1753-318X.2011.01112.x 